\title{
TRANSVAGINAL SONOSALPINGOGRAPHY VERSUS HYSTEROSALPINGOGRAPHY AND LAPAROSCOPIC CHROMOPERTUBATION- A COMPARATIVE EVALUATION FOR DETERMINATION OF TUBAL PATENCY
}

\author{
Sachin Wankhede', Sarika Thakare2, Nivedita Goverdhan ${ }^{3}$
}

${ }^{1}$ Associate Professor, Department of Obstetrics and Gynaecology, Indira Gandhi Government Medical College, Nagpur. ${ }^{2}$ Assistant Professor, Department of Obstetrics and Gynaecology, Indira Gandhi Government Medical College, Nagpur. ${ }^{3}$ Senior Resident, Department of Obstetrics and Gynaecology, Indira Gandhi Government Medical College, Nagpur.

ABSTRACT

\section{BACKGROUND}

The aim of this study was to assess usefulness of sonosalpingography in determining role of tubal factor in cases of infertility as an initial measure as compared to hysterosalpingography and diagnostic laparoscopy.

\section{MATERIALS AND METHODS}

This was a descriptive study conducted over a period of 9 months. 50 patients with infertility attending the infertility clinic in OPD of Obstetrics and Gynaecology were evaluated clinically with detailed history. All patients were subjected to sonosalpingography, hysterosalpingography and laparoscopy and the findings were documented.

\section{RESULTS}

There were 40 cases (80\%) with primary infertility and $10(20 \%)$ with secondary infertility. Sonosalpingography has $94.87 \%$ sensitivity rate with laparoscopic chromopertubation as reference standard whereas hysterosalpingography has $87.17 \%$ sensitivity rate. Laparoscopy has better diagnosis rate than HSG and sonosalpingography in pelvic pathologies.

\section{CONCLUSION}

Sonosalpingography is a simple office noninvasive procedure having slightly better diagnostic value than HSG and somewhat similar to laparoscopy for determining tubal patency. We conclude that all patients with infertility should undergo sonosalpingography as an initial measure to assess tubal patency as part of their primary workup of infertility.

\section{KEYWORDS}

Infertility, Sonosalpingography, HSG, Diagnostic Laparoscopy, Tubal Patency.

HOW TO CITE THIS ARTICLE: Wankhede S, Thakare S, Goverdhan N. Transvaginal sonosalpingography versus hysterosalpingography and laparoscopic chromopertubation- a comparative evaluation for determination of tubal patency. J. Evolution Med. Dent. Sci. 2017;6(10):749-752, DOI: 10.14260/Jemds/2017/162

\section{BACKGROUND}

Infertility has not only been a source of personal misery, a cause of disgrace and divorce since ancient times. It continues to be a major medical and social problem even today. Infertility affects nearly $10-15 \%$ of couples and is an important part of clinical practice. ${ }^{1}$ Leading causes of infertility include tubal disease, ovulatory disorders, uterine or cervical factors, endometriosis and male factor infertility. The female factor contributes most (i.e. $40-45 \%$ ) to aetiologies of infertility followed by male factor (32-40\%), both partners $(10 \%)$ and unexplained $(10 \%)$. $^{2}$

The Tubal factors contribute almost $40-45 \%$ cases of female infertility. The appropriate selection of investigations based on problem areas identified by history and physical examination would guide the gynaecologist in the management of infertile couples. Diagnostic laparoscopy is invasive and has its share of morbidity and sometimes mortality also. HSG requires the patient to be subjected to radiation

Financial or Other, Competing Interest: None.

Submission 27-12-2016, Peer Review 19-01-2017,

Acceptance 25-01-2017, Published 02-02-2017.

Corresponding Author:

Dr. Sachin Wankhede,

Department of Obstetrics and Gynaecology,

Indira Gandhi Government Medical College,

Nagpur.

E-mail: drsachinwankhede@yahoo.co.in

DOI: $10.14260 /$ jemds $/ 2017 / 162$ to determine tubal patency. Our study assesses tubal patency by all the three methods and compares the observations.

\section{MATERIALS AND METHODS}

This is a descriptive study, carried out in the Department of Obstetrics and Gynaecology at Indira Gandhi Government Medical College and Hospital Nagpur over a period of 9 months. 50 patients with female factors of infertility attending the infertility clinic in OPD of Obstetrics and Gynaecology were selected and informed about the study and risk associated with it. Study subjects were evaluated clinically with detailed history. All patients were subjected to sonosalpingography, hysterosalpingography and laparoscopy and the findings were documented.

Sonosalpingography was done on sixth or seventh day, HSG on eighth or ninth day and diagnostic laparoscopy with chromopertubation was done on twenty first to twenty third day of menstrual cycle.

\section{Procedure of Sonosalpingography}

Informed written consent was obtained after explaining the procedure. Using all aseptic precautions sterile normal saline was instilled in uterine cavity through a no 10 Foley's catheter placed just above the internal os during transvaginal sonography. The catheter balloon was distended with $3 \mathrm{ml}$ of normal saline to avoid retrograde leakage through vagina.

The uterus was scanned and the entire endometrial cavity delineated. Tubes were inspected for spillage. Prophylactic antibiotic course was given. 
RESULTS

Table-1

\begin{tabular}{|c|c|c|c|}
\hline & & Primary Infertility & Secondary Infertility \\
\hline \multirow{2}{*}{$\begin{array}{c}\text { Age } \\
\text { (years) }\end{array}$} & Range & $20-37$ & $24-35$ \\
\hline & Mean & 26.8 & 28.75 \\
\hline \multirow{2}{*}{ Duration of Infertility (years) } & Range & $2-13$ & $2-15$ \\
\hline & Mean & $5.11 \pm 2.61$ & $5.13 \pm 2.88$ \\
\hline \multicolumn{2}{|c|}{ Total No. of patients } & 40 & 10 \\
\hline
\end{tabular}

In this study the maximum number of cases 23 (46\%) were in the age group 21-25 years. There were $40(\%)$ cases infertility. Most cases were with duration of 3-5 years of of primary infertility and 10 cases $(20 \%)$ of secondary

Table-2

\begin{tabular}{|c|c|c|c|c|}
\hline Test & $\begin{array}{c}\text { Both Tubes } \\
\text { Patent }\end{array}$ & $\begin{array}{c}\text { Bilateral Tubal } \\
\text { Blockage }\end{array}$ & RT tube Patent & LT tube Patent \\
\hline Sonosalpingography & 37 & 4 & 4 & 5 \\
\hline Hysterosalpingography & 34 & 6 & 3 & 7 \\
\hline \multicolumn{2}{|c|}{ Laparoscopic chromopertubation } & 39 & 3 & 3 \\
\hline
\end{tabular}

Table 2. Distribution of study subjects according to tubal patency $(n=50)$

In the present study sonosalpingography has $94.87 \%$ sensitivity while HSG recorded a slightly less $87.17 \%$ sensitivity rate.

In 1 case, we got false positive result in right tube because of the presence of hydrosalpinx. The tube was patent on sonosalpingography but blockage was seen in laparoscopy and HSG. The flow of saline through the dilated tubes may look like spillage on sonography. In 1 case false negative result was obtained which may be due to cornual spasm, mucus blockage or technical error.

Table-3

\begin{tabular}{|c|c|c|c|}
\hline Findings & Laparoscopy & Hysterosalpingography & Sonosalpingography \\
\hline Hydrosalpinx & 5 & 2 & 3 \\
\hline Tubo ovarian mass & 1 & 0 & 2 \\
\hline Endometriosis & 3 & 0 & 2 \\
\hline Polycystic ovary & 2 & 0 & 1 \\
\hline Ovarian cysts & 3 & 0 & 3 \\
\hline Peritubal adhesions & 3 & 0 & 0 \\
\hline Total & $\mathbf{1 7}$ & $\mathbf{2}$ & $\mathbf{1 1}$ \\
\hline
\end{tabular}

Table 3. Distribution of study subjects according to other associated pelvic findings

Laparoscopy was found to be far more efficient in detecting pelvic pathologies as compared to both HSG and sonosalpingography.

\section{DISCUSSION}

There are few subjects of late that have evoked more debates, discussions and disagreements in gynaecology than the evaluation and management of the infertile couple. Age is an important factor for the prediction of chances for spontaneous conception in both untreated patients and patients who are being treated for infertility. Fertility in women peaks between the ages of 20 and 24, decreases relatively little till the age of 30 and then declines progressively. ${ }^{3}$ In this study the maximum number 23 cases (46\%) were in the age group 21-25 years. Similar findings were seen by Kanal $\mathrm{P}$ and Sharma $\mathrm{S}^{4}$ and Boricha $\mathrm{Y}$ et $\mathrm{al}^{5}$ who quoted maximum cases of infertility (45\%) in age group of $21-25$ years and $42.85 \%$ in the age group of $21-25$ years respectively.

Mehreen $\mathrm{B}$ et $\mathrm{al}^{6}$ revealed that maximum number of patients $(45.71 \%)$ presented with $2-5$ years of infertility, similar to our study. Less than 10 years duration of infertility did not significantly affect the conception rate in patients undergoing treatment for infertility. However, duration longer than 10 years showed an exponential decrease in conception rates according to a study by Dechanet et $\mathrm{al}^{7}$ Similar findings were reported by a study by Wilkes et al. ${ }^{8}$

On comparing the results of sonosalpingography, HSG and laparoscopy we found that the sensitivity of sonosalpingography is $94.87 \%$ and of HSG is $87.17 \%$. Kore et $\mathrm{al}^{9}$ also found that when results of sonosalpingography were compared with those of laparoscopy $97 \%$ correlation was noted whereas there was $93 \%$ correlation between the results of HSG and laparoscopy. Seal Subrata Lall, et al ${ }^{10}$ also in their study found that sonosalpingography has $97.3 \%$ sensitivity and HSG has $94.6 \%$ sensitivity in comparison to laparoscopic chromopertubation. Yasmeen Usmani et al ${ }^{11}$ found that sonosalpingography has a sensitivity of $86.6 \%$ when compared with laparoscopy in the assessment of tubal patency.

In the study by Preeti Deshpande et al 12 they found that there was complete agreement in $90 \%$ cases, partial agreement in $6.6 \%$ cases and total disagreement in $3.3 \%$ cases. Rubin in 1920 introduced the tubal insufflation test using $\mathrm{CO} 2$ to investigate tubal patency. Subsequently HSG was the method of choice more so after the advent of water soluble contrast media. 


\section{HSG has certain disadvantages-}

A. Detects only the endotubal pathology.

B. Sometimes causes allergic manifestations and reactions to the drug used.

C. Known hydrosalpinx, acute PID, cervicitis and adnexal mass all are contraindications.

D. Exposes women to radiation.

Since the advent of ultrasound, it is being used in the treatment of infertility. Nannini et al ${ }^{13}$ Richman et al ${ }^{14}$ and Randolph et $\mathrm{al}^{15}$ were the pioneers of using exogenous contrast medium for ultrasound visualisation of the internal genital tract.

Laparoscopy is currently regarded as the most reliable tool in the diagnosis of tubal causes of subfertility. Since laparoscopy visualises the morphological abnormalities of fallopian tubes directly, it is generally accepted as the reference standard for determination of the accuracy of other diagnostic tools such as HSG or Chlamydia Ab testing for tubal pathology.

\section{Laparoscopy has its own Concerns also-}

A. It is an invasive procedure.

B. Has risks of anaesthesia.

C. Requires preoperative investigations.

D. Admission.

E. Mental preparation of the patient for the procedure.

HSG has the advantage of detecting the site of blockage, isthmica nodosa, benign polyps and tubal endometriosis.

Transvaginal transducer of high frequency allows better visualisation of the genital organs. It also allows evaluation of tubal patency. Sonosalpingography has also certain advantages. It is an outpatient procedure, less time consuming and cost effective. It is a noninvasive procedure and does not require anaesthesia and operation theatre. It carries no radiation hazards and avoids allergic reactions seen with HSG. Tubal patency can be shown to patients in real time. It is reliable for assessment of tubal patency. It helps in the diagnosis of uterine anomalies and pelvic pathologies.

Sonosalpingography has its limitations as well. Tubal spasm may lead to diagnosis of tubal occlusion. Tubal flow may give a false impression of tubal patency in hydrosalpinx. Intratubal pathology cannot be detected. Site of blockage cannot be detected precisely. Peritubal adhesions and motility of the tubes cannot be assessed properly.

Combining sonosalpingography with transvaginal sonography provides a fair insight to diagnose other causes of infertility also in addition to diagnosing tubal patency. It may also be used to assess tubal status after microsurgery for anastomosis and is clearly indicated in patients with no history of reactions to iodinated contrast material.

Ayida and co-workers ${ }^{16}$ have suggested that laparoscopy and chromopertubation have no place as a primary test for tubal patency in a non-complicated patient (A patient without a history of pelvic inflammatory disease, endometriosis or genital tract anomaly).

Thus, sonosalpingography offers a much less invasive method of diagnosing tubal patency while maintaining a high sensitivity similar to that of laparoscopic chromopertubation. Moreover, sonosalpingography can be done for patients who have bronchial asthma or cardiac problems and are temporarily unfit for surgery. ${ }^{17,18,19}$

\section{CONCLUSION}

Sonosalpingography is a simple, cost effective, non-invasive procedure for testing tubal patency and should be employed as initial test to assess tubal patency. If any abnormality is detected on sonosalpingography, HSG or laparoscopy can be done for confirmation.

\section{REFERENCES}

[1] Mosher WD, Pratt WF. Fecundity and infertility in the United States: incidence and trends. Fertil Steril 1991;56(2):192-3.

[2] Padubidri VG, Shirish DN. The pathology of conception. Shaw's text book of gynaecology. 12th edn. BI Churchill Livingstone, New Delhi 1983:154-68.

[3] Maroulis G. Effect of aging on fertility and pregnancy. Seminars Reprod Endocrinol 1991;9:165.

[4] Kanal P, Sharma S. Study of primary infertility in females by diagnostic laproscopy. Internet Journal of Medical Update 2006;1(2):7-9.

[5] Boricha Y, Sharma R, Boricha B, et al. Laparoscopy in 50 infertile couples: prospective study. International Journal of Medical and Clinical Research 2011;2(2):636.

[6] Mehreen B, Batool WS, Tahir KM. Diagnostic significance of laparoscopy in infertility \& identification of various unsuspected factors associated with infertility in females. J Pharm Sci \& Res 2010;2(8):499505.

[7] Dechanet C, Belaisch-Allart J, Hédon B. Prognosis criteria for the management of the infertile couple. J Gynecol Obstet Biol Reprod 2010;39(8 Suppl 2):S9-26.

[8] Wilkes S, Chinn DJ, Murdoch A, et al. Epidemiology and management of infertility: a population-based study in UK primary care. Family Practice 2009;26(4):269-74.

[9] Kore S, Hegde A, Nair S, et al. Sonography for assessment of tubal patency: our experience. J Obstet Gynecol India 2000;50(2):63-6.

[10] Lalls SS, Debdulta G, Debdas S, et al. Comparative evaluation of sonosalpingography hysteronsalpingography and laproscopy for determination of tubal patency. J obstet gynecol India 2007;57(2):158-61.

[11] Usmani Y, Pandey VD, Ekrumullah, et al. A comparative study between sonosalpingography and laproscopic chromopertubation for tubal evaluation. Sch J App Med Sci 2016;4(6F):2266-70.

[12] Deshpande P, Deshpande S. Sono Hysterosalpingography shsg: a useful adjuvant in infertility evaluation. Jemds 2015;4(10):1628-33.

[13] Nannini R, Chelo E, Branconi F, et al. Dynamic echohysteroscopy: a new diagnostic technique in the study of female infertility. Acta Eur Fertil 1981;12(2):165-71.

[14] Richman TS, Viscomi GN, deCherney A, et al. Fallopian tubal patency assessed by ultrasound following fluid injection. Work in progress. Radiology 1984;152(2):507-10.

[15] Randolph JF, Ying YK, Maier DB, et al. Comparison of real time ultrasonography, hysterosalpingography, and laproscopy/hysteroscopy in the evaluation of uterine abnormalities and tubal patency. Fertil Steril 1986;46(5):828-32. 
[16] Ayida G, Chamberlain P, Barlow D, et al. Is routine diagnostic laproscopy for infertility still justified? A pilot study assessing the use of hysterosalpingo-contrast sonography and magnetic resonance imaging. Hum Reprod 1997;12(7):1436-9.

[17] Kiyokawa K, Masuda H, Fuyuki T, et al. Three dimensional hysterosalpingo-contrast sonography as an outpatient procedure to assess infertile women: a pilot study. Ultrasound Obstet Gynecol 2000:16(7):648-54.
[18] Bonammy L, Marett H, Perotin F, et al. Sonohysterography: a prospective survey of results and complications in 81 patients. Eur J Obstet gynawl reproductive Biology 2002;102(1):42-7.

[19] Zvanca M. Infertility investigation through saline infusion sonohysterosalpingography. MAEdica- A Journal of Clinical Medicine 2007;2(1):10-7. 